\title{
Simulating stress-dependent fluid flow in a fractured core sample using real-time $\mathrm{X}$-ray $\mathrm{CT}$ data
}

\author{
Tobias Kling ${ }^{1}$, Da Huo ${ }^{2}$, Jens-Oliver Schwarz ${ }^{3,4}$, Frieder Enzmann ${ }^{3}$, Sally Benson ${ }^{2}$, and Philipp Blum ${ }^{1}$ \\ ${ }^{1}$ Institute for Applied Geosciences (AGW), Karlsruhe Institute of Technology (KIT), Karlsruhe, 76131, Germany \\ ${ }^{2}$ School of Earth Sciences, Stanford University, Stanford, CA 94305-2210, USA \\ ${ }^{3}$ Institute for Geosciences, Johannes Gutenberg University of Mainz, Mainz, 55128, Germany \\ ${ }^{4}$ Math2Market GmbH, Kaiserslautern, 67657, Germany \\ Correspondence to: Tobias Kling (tobias.kling@kit.edu)
}

Received: 29 February 2016 - Published in Solid Earth Discuss.: 10 March 2016

Revised: 16 June 2016 - Accepted: 26 June 2016 - Published: 19 July 2016

\begin{abstract}
Various geoscientific applications require a fast prediction of fracture permeability for an optimal workflow. Hence, the objective of the current study is to introduce and validate a practical method to characterize and approximate single flow in fractures under different stress conditions by using a core-flooding apparatus, in situ X-ray computed tomography $(\mathrm{CT})$ scans and a finite-volume method solving the Navier-Stokes-Brinkman equations. The permeability of the fractured sandstone sample was measured stepwise during a loading-unloading cycle ( 0.7 to $22.1 \mathrm{MPa}$ and back) to validate the numerical results. Simultaneously, the pressurized core sample was imaged with a medical X-ray CT scanner with a voxel dimension of $0.5 \times 0.5 \times 1.0 \mathrm{~mm}^{3}$. Fracture geometries were obtained by CT images based on a modification of the simplified missing attenuation (MSMA) approach. Simulation results revealed both qualitative plausibility and a quantitative approximation of the experimentally derived permeabilities. The qualitative results indicate flow channeling along several preferential flow paths with less pronounced tortuosity. Significant changes in permeability can be assigned to temporal and permanent changes within the fracture due to applied stresses. The deviations of the quantitative results appear to be mainly caused by both local underestimation of hydraulic properties due to compositional matrix heterogeneities and the low CT resolution affecting the accurate capturing of sub-grid-scale features. Both affect the proper reproduction of the actual connectivity and therefore also the depiction of the expected permeability hysteresis. Furthermore, the threshold value $\mathrm{CT}_{\text {mat }}(1862.6 \mathrm{HU})$ depicting the matrix material represents the most sensitive input
\end{abstract}

parameter of the simulations. Small variations of $\mathrm{CT}_{\text {mat }}$ can cause enormous changes in simulated permeability by up to a factor of $2.6 \pm 0.1$ and, thus, have to be defined with caution. Nevertheless, comparison with further CT-based flow simulations indicates that the proposed method represents a valuable method to approximate actual permeabilities, particularly for smooth fractures $(<35 \mu \mathrm{m})$. However, further systematic investigations concerning the applicability of the method are essential for future studies. Thus, some recommendations are compiled by also including suggestions of comparable studies.

\section{Introduction}

Naturally and artificially induced hydromechanical coupling is essential for the understanding of many geologic processes within the Earth's crust and for the successful realization of a wide range of geoscientific applications. A more detailed overview about these applications such as geothermal energy generation, nuclear waste disposal or hydrocarbon production is presented by Rutqvist and Stephansson (2003). Since there are different phenomena of direct and indirect hydromechanical coupling in geosciences, this study only deals with the direct solid-to-fluid coupling, which is defined as the stress-induced changes in fluid dynamics (Wang, 2000).

In the past, the stress dependency of fracture permeability and its hysteretic behavior due to stepwise loading and subsequent unloading were investigated by various authors (e.g., Gangi, 1978; Kranz et al., 1979; Snow, 1965). Various 
empirical models were developed that approximate stressdependent fracture permeability by adding roughness-based variables to the common cubic law approach (Bernabe, 1986; Gale, 1982; Gangi, 1978; Huo and Benson, 2015; Swan, 1983; Walsh, 1981; Witherspoon et al., 1980; Zimmerman et al., 1992). However, flow in rough fractures is governed by several additional morphology-related features, such as the grade of connectivity, variations in tortuosity, flow separation and stagnant zones (Konzuk and Kueper, 2002; Tsang, 1984), that are hard to quantify empirically.

Hence, numerical simulations that allow the implementation of much more sophisticated physical solution approaches and boundary conditions represent a powerful tool in modern geosciences. Accordingly, there is an immense number of computational fluid dynamics (CFD) studies concerning different topics such as single-phase and multi-phase flow (Sahimi, 2011), natural (Crandall et al., 2010) and artificial fractures (Brush and Thomson, 2003) or fractured porous media (Landry and Karpyn, 2012). The same applies to CFD methods, which are most frequently represented by finitedifference, finite-element, lattice gas and lattice Boltzmann methods (Madadi and Sahimi, 2003). In particular, the lattice methods are suggested by Madadi and Sahimi (2003) as the ideal computational base for arbitrary geometries. In addition to that, the finite-volume method has been increasingly and successfully used to simulate fracture flow in the last few years (Al-Yaarubi et al., 2005; Brush and Thomson, 2003; Crandall et al., 2010; Huber et al., 2012; Schwarz and Enzmann, 2013). However, in practice, solving three-dimensional (3-D) mathematical models such as the Navier-Stokes equation with these methods can be computationally elaborate so that many simulations prefer simplified flow models such as the "local cubic law" approach (Brush and Thomson, 2003; Konzuk and Kueper, 2004; Koyama et al., 2008; Oron and Berkowitz, 1998; Zimmerman and Yeo, 2013).

Various studies concerning numerical simulations of stress-dependent fracture flow in core-scale dimensions have been performed until now. Table 1 provides a chronological list of previously performed studies. All these simulations focus on dynamic changes of fracture permeability due to loading conditions. However, they do not address residual changes as a result of mechanical deformation within the fracture, which can be addressed by subsequent unloading. Except the study by Watanabe et al. (2008), who highlight qualitative insights into the flow structures, all other studies in Table 1 quantify and intend to validate simulated fracture flow. In a subsequent study which is not listed in Table 1, Watanabe et al. (2009) applied a similar (non-quantitative) procedure for other fracture types. By contrast, quantification of fracture flow was performed by Indraratna et al. (2015), who performed CFD simulations based on initial laser-scanning measurements, where the flow model is coupled with a deformation criteria simulating fracture closing. Similar, but more simplified, defor- mation procedures were performed for statistically derived aperture distributions (Pyrak-Nolte and Morris, 2000), profilometer measurements (Kim et al., 2003), laser-scan data (Nemoto et al., 2009; Watanabe et al., 2008, 2009) and a conceptual 2-D model (Liu et al., 2010). Furthermore, Dicman et al. (2004) described changes in aperture distribution by combining laboratory data and stochastic approaches. Considering this study and further information provided in Table 1, most of the used fracture geometries can be assumed to be not directly correlated to the actual fracture geometries under loading conditions used for validation. For this reason, more recent studies introduced X-ray computed tomography (CT) that enables the scanning of in situ conditions during the experiment within the sample and creates "real-time" images of the fracture (Watanabe et al., 2011, 2013).

In the past, in situ imaging of experiments based on CT technologies was applied to a wide range of studies including geomechanical behavior of fractures (Re and Scavia, 1999), evaluations of triaxial tests (Feng et al., 2004; Ge et al., 2001; Lenoir et al., 2007; Ren and Ge, 2004; Vinegar et al., 1991; Zhou et al., 2008), shear tests (Tatone and Grasselli, 2015), sand production experiments (Santos et al., 2010) as well as various single-/multi-phase core-flooding experiments in fractured and unfractured rocks (Huo and Benson, 2015; Krevor et al., 2012; Oh et al., 2013; Perrin and Benson, 2010; Pini and Benson, 2013; Pini et al., 2012; Rangel-German et al., 2006; Schembre and Kovscek, 2003; Shi et al., 2009; Watanabe et al., 2011). CT technology generally represents a 3-D non-destructive method to image material contrasts in high resolution and, therefore, is well suited to reproduce dynamic processes in situ and in "real time". Detectable material contrasts can be caused by significant changes in density, such as the transition from solid to air, or chemical composition affecting the X-ray attenuation. In this study, the term "real time" refers to a non-continuous but stepwise imaging of a sample being subjected to a dynamic process.

Comparing other appliances such as industrial, micro- or synchrotron-based CTs, medical CT scanners admittedly operate with the lowest resolutions. However, they generally have the advantage of lower scanning times and are more flexible in terms of sample/equipment weights and sizes (Watanabe et al., 2011). Currently, medical CT scanners represent the most economical option to conduct such experiments and also provide, particularly in regard to their importance in medicine, a good accessibility.

The central issue concerning CT measurements and fractured rocks is given by the aperture calibration based on measured material contrasts. Considering a transect perpendicular to the fracture plane, there are generally four methods to calibrate apertures caused by the fracture-related density anomaly (Ketcham and Carlson, 2001; Ketcham et al., 2010). (1) The peak height (PH) method is based on the gap between the idealized matrix density and the negative peak of the anomaly, which was successfully applied by Watanabe et al. (2011) but typically is more applicable for homo- 
Table 1. Numerical simulations of stress-dependent single-phase fracture flow considering the sample and fracture type, the method to reproduce fracture apertures, the model dimensions and simulation methods.

\begin{tabular}{|c|c|c|c|c|c|c|}
\hline References & $\begin{array}{l}\text { Core sample } \\
\text { (length/diameter) }\end{array}$ & Fracture type & $\begin{array}{l}\text { Source of model geometry } \\
\text { (aperture translation method) }\end{array}$ & $\begin{array}{l}\text { Volume element dimension } \\
\text { (represented fracture area) }\end{array}$ & Dimensions & $\begin{array}{l}\text { Simulation type } \\
\text { (Solver) }\end{array}$ \\
\hline $\begin{array}{l}\text { Pyrak-Nolte and } \\
\text { Morris (2000) }\end{array}$ & $\begin{array}{l}\text { Granites } \\
\text { (literature data) }\end{array}$ & Artificial & $\begin{array}{l}\text { Fractal aperture distributions } \\
\text { (stratified percolation method) }\end{array}$ & $\begin{array}{l}300 \times 300 \text { cubic grid blocks } \\
\left(100 \times 100 \mathrm{~mm}^{2}\right)\end{array}$ & $2.5-\mathrm{D}$ & $\begin{array}{l}\text { Network model } \\
\text { (Hardy-Cross method) }\end{array}$ \\
\hline Kim et al. (2003) & $\begin{array}{l}\text { Granite } \\
(16.4 \mathrm{~cm} / 14.0 \mathrm{~cm})\end{array}$ & $\begin{array}{l}\text { Tensile } \\
\text { (mated and offset) }\end{array}$ & $\begin{array}{l}\text { Profilometer } \\
\text { measurements }\end{array}$ & $\begin{array}{l}0.05 \times 0.05 \times>0.008 \mathrm{~mm}^{3} \\
\left(111 \text { to } 116 \times 128 \mathrm{~mm}^{2}\right)\end{array}$ & 3-D & $\begin{array}{l}\text { Lattice Boltzmann } \\
\text { (Navier-Stokes) }\end{array}$ \\
\hline Dicman et al. (2004) & $\begin{array}{l}\text { Sandstone } \\
(2.54 \mathrm{~cm} / 5.99 \mathrm{~cm})\end{array}$ & Tensile & $\begin{array}{l}\text { Average aperture (stochastic } \\
\text { aperture distribution map) }\end{array}$ & $\begin{array}{l}1 \times 1 \times 1 \text { grid block } \\
(10 \times 10 \times 15 \text { grid blocks })\end{array}$ & 3-D & $\begin{array}{l}\text { Finite difference } \\
\text { (local cubic law) }\end{array}$ \\
\hline Watanabe et al. (2008) & $\begin{array}{l}\text { Granite } \\
(15.0 \mathrm{~cm} / 10.0 \mathrm{~cm})\end{array}$ & $\begin{array}{l}\text { Tensile } \\
\text { (mated and offset) }\end{array}$ & $\begin{array}{l}\text { Laser-scanning } \\
\text { equipment }\end{array}$ & $\begin{array}{l}0.25 \times 0.25 \mathrm{~mm}^{2} \\
\text { (sample scale) }\end{array}$ & 2.5-D & $\begin{array}{l}\text { Finite difference } \\
\text { (local cubic law) }\end{array}$ \\
\hline Nemoto et al. (2009) & $\begin{array}{l}\text { Granite } \\
(15.0 \mathrm{~cm} / 9.5 \mathrm{~cm})\end{array}$ & $\begin{array}{l}\text { Shear fracture for experiment, } \\
\text { tensile (offset) for simulation }\end{array}$ & $\begin{array}{l}\text { Laser-scanning equipment } \\
\text { and thin film technique }\end{array}$ & $\begin{array}{l}0.25 \times 0.25 \mathrm{~mm}^{2} \\
\left(50 \times 50 \mathrm{~mm}^{2}\right)\end{array}$ & $2.5-\mathrm{D}$ & $\begin{array}{l}\text { Finite difference } \\
\text { (local cubic law) }\end{array}$ \\
\hline Liu et al. (2010) & $\begin{array}{l}\text { Coal and Sandstone } \\
(10.0 \mathrm{~cm} / 5.0 \mathrm{~cm})\end{array}$ & Shear fracture & Conceptual side view & $\begin{array}{l}100 \times 25 \\
\text { four-node mesh (none) }\end{array}$ & 2-D & $\begin{array}{l}\text { Finite element (fluid/solid } \\
\text { coupling model) }\end{array}$ \\
\hline $\begin{array}{l}\text { Watanabe et al. (2011), } \\
\text { Watanabe et al. (2013) }\end{array}$ & $\begin{array}{l}\text { Granite } \\
(15.0 \mathrm{~cm} / 10.0 \mathrm{~cm})\end{array}$ & $\begin{array}{l}\text { Tensile (mated) and } \\
\text { natural (double fractured) }\end{array}$ & $\begin{array}{l}\text { Medical CT scanner } \\
\text { (peak height method) }\end{array}$ & $\begin{array}{l}0.35 \times 0.35 \times 0.50 \mathrm{~mm}^{3} \\
(\text { sample scale) }\end{array}$ & 3-D & $\begin{array}{l}\text { Finite difference } \\
\text { (local cubic law) }\end{array}$ \\
\hline Indraratna et al. (2015) & $\begin{array}{l}\text { Sandstone } \\
(11.4 \mathrm{~cm} / 5.4 \mathrm{~cm})\end{array}$ & $\begin{array}{l}\text { Tensile } \\
\text { (mated) }\end{array}$ & $\begin{array}{l}\text { Laser-scanning } \\
\text { equipment }\end{array}$ & $\begin{array}{l}1.0 \times 1.0 \mathrm{~mm}^{2} \\
(\text { sample scale) }\end{array}$ & $2.5-\mathrm{D}$ & $\begin{array}{l}\text { Finite volume } \\
\text { (Navier-Stokes) }\end{array}$ \\
\hline Current & $\begin{array}{l}\text { Sandstone } \\
(6.7 \mathrm{~cm} / 5.0 \mathrm{~cm})\end{array}$ & $\begin{array}{l}\text { Saw cut } \\
\text { (smooth, mated) }\end{array}$ & $\begin{array}{l}\text { Medical CT scanner } \\
\text { (missing attenuation method) }\end{array}$ & $\begin{array}{l}0.50 \times 0.50 \times 1.00 \mathrm{~mm}^{3} \\
(\text { sample scale })\end{array}$ & 3-D & $\begin{array}{l}\text { Finite volume } \\
\text { (Navier- } \\
\text { Stokes-Brinkman) }\end{array}$ \\
\hline
\end{tabular}

geneous materials (Ketcham et al., 2010). The PH method requires a careful calibration. 2) The missing attenuation (MA) method, which integrates the entire anomaly area, was meanwhile refined for smaller apertures and can also be used for heterogeneous rocks and, theoretically, does not require calibration (Huo et al., 2016). (3) The full-width-halfmaximum (FWHM) method uses the midpoint between matrix and peak value; however, it is only applicable to larger apertures (Ketcham, 2010) and less accurate than the MA method (Van Geet and Swennen, 2001). (4) The inverse point-spread function (IPSF) method represents a hybrid between PH and MA methods and iteratively reconstructs fractures by using a IPSF accounting for the blurring of the CT image. Indeed, IPSF method is well suitable to calculate apertures and also is applicable for heterogeneous materials. However, this method is computationally expensive due to the complex numerical deconvolution (Ketcham et al., 2010). Indeed, Watanabe et al. (2011) introduced a useful method to simulate stress-dependent fluid flow based on CT images and in fracture-scale before. However, their method revealed several limitations: (A) simulations are very sensitive to image noise due to the core holder; (B) the aperture calibration that is based on the PH method needs a careful and very time-consuming calibration; and (C) the applied CFD simulation relies on a simplified fluid dynamics represented by the "local cubic law" approach. Particularly for field work, where time often plays a significant role, a functional approach without time-consuming operation procedure and costly equipment can be an asset. Thus, a method would be necessary that only requires a fast CT scan of a pressurized dry sample to predict fluid flow under predefined boundary conditions.
The objective of this study is therefore to propose a practical approach based on real-time X-ray CT data to numerically validate and reproduce stress-dependent single-phase fluid flow in a fractured sandstone sample. This simulation approach consists of (1) an aperture calibration approach for 3-D simulations based on a modification of the simplified MA method (MSMA) and (2) a sophisticated simulation method that accounts for fracture and matrix flows by solving the Navier-Stokes-Brinkman equation. To demonstrate the effectiveness of this method and to also indicate the transferability to real reservoir rocks such as an enhanced geothermal system (EGS), a fractured low-permeable sample is used. In the present study, the fluid flow is simulated under loading and unloading conditions to prove the extent to which it is possible to reproduce flow characteristics and residual fracture changes. Imaging is performed by simultaneously conducting medical CT scans and core-flooding experiments, allowing the validation of the simulated results. Furthermore, current simulations are compared to corresponding studies (Watanabe et al., 2011, 2013) providing various insightful recommendations for the successful implementations of future CT-based CFD simulations.

\section{Material and methods}

\subsection{Sample}

In this study a Zenifim sandstone is used, which was obtained from the former (unproductive) hydrocarbon prospection well Ramon-1 located in the central Negev area in southern Israel (Fig. 1). The rock belongs to the sea marginal deposits of the arkosic Zenifim Formation (Precambrian age) 


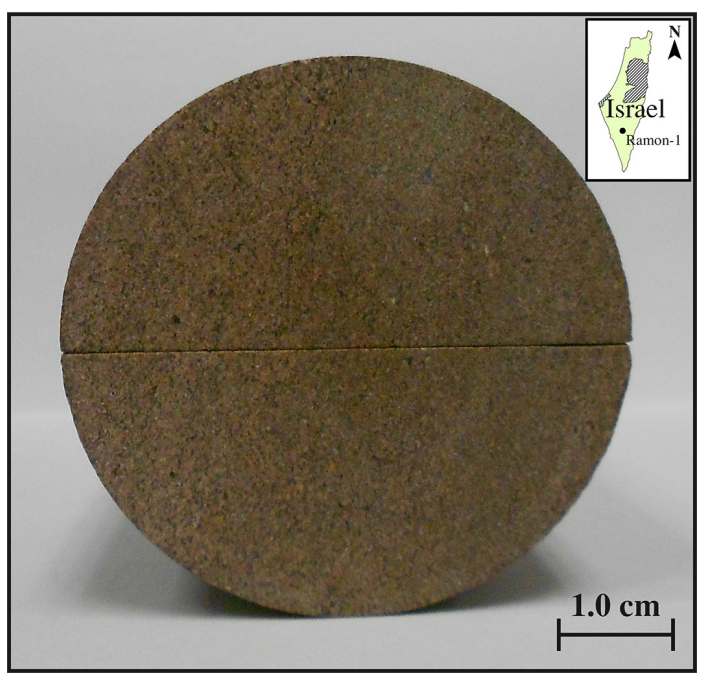

Figure 1. Top view of the fractured Zenifim Sandstone with a diameter of $5.0 \mathrm{~cm}$ and a length of $6.7 \mathrm{~cm}$.

and originates from $1770 \mathrm{~m}$ below surface. Additional information on geology and stratigraphy can be obtained by Weissbrod and Sneh (2002). According to Huo and Benson (2015), who used the same sample in their study, the sample is sedimentologically classified as an immature feldspathic greywacke. The sample is composed of poorly sorted and rounded grains with a mean grain size of $0.2 \mathrm{~mm}$. The matrix is cemented by quartz resulting in low mean permeability of $5.92 \times 10^{-19} \mathrm{~m}^{2}$ and porosity of 2.5 to $3.9 \%$ with a bulk density of $2,490 \mathrm{~kg} \mathrm{~m}^{-3}$ (mercury injection capillary pressure (MICP) analysis). However, microscopic analyses (Huo and Benson, 2015) and visible fine laminations with a thickness of a few millimeters, which dip towards the core axis, indicate a significant porosity heterogeneity within the core.

The utilized rock sample is a continuously cylindrical core sample with a length of $6.7 \mathrm{~cm}$ and a diameter of $5.0 \mathrm{~cm}$ (Table 1, Fig. 1). Before the coupled experiments, the sample was bisected along the core axis by generating a sawcut fracture intersecting the previously mentioned laminations resulting in a discontinuity, which can be described as a (mated) smooth-walled and relatively tight fracture. It should be noted that abrasion processes and local grain disruptions due to the sawing process result most likely in some minor artifacts along the fracture surface.

\subsection{Experiment}

An aluminum core holder was used for the core-flooding experiment (Fig. 2). This experimental setup is based on the a porosity heterogeneity study by Perrin and Benson (2010) and was modified and successfully adapted for core-flooding experiments in porous (Pini et al., 2012) and fractured rocks (Huo and Benson, 2015). The fractured core is positioned in

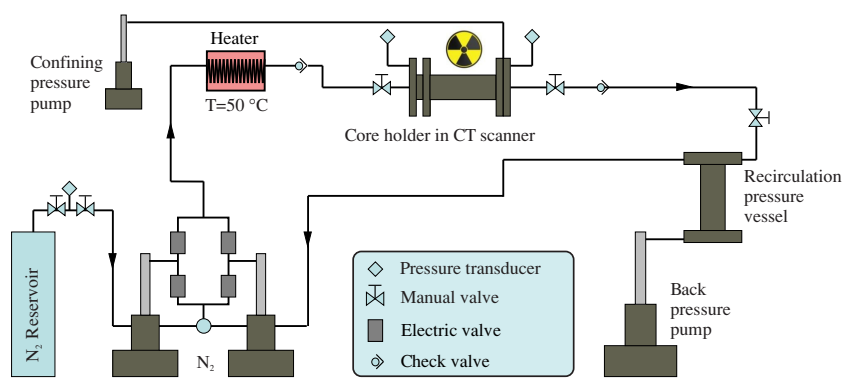

Figure 2. Schematic setup of the core-flooding apparatus for singlephase $\left(\mathrm{N}_{2}\right)$ flow experiments (after Huo and Benson, 2015).

an aluminum core holder with alternating interlayers of Viton rubber, heat-shrinkable Teflon and nickel foil that can also be seen on the CT image (Fig. 3). For further technical details please refer to Huo and Benson (2015), who used the same experimental setup.

Permeability measurements of the core sample are based on the steady-state method. After saturating the encapsulated sample with nitrogen $\left(\mathrm{N}_{2}\right)$, three different flow rates $(12,16$ and $20 \mathrm{~mL} \mathrm{~min}^{-1}$ ) are successively applied. A constant pore pressure of $2.1 \mathrm{MPa}$ is applied to suppress the slippage effect. Hence, the applied low flow rates and corresponding small pressure drops reveal a linear relationship indicating laminar fluid flow. Hence, in this study the fluid can be treated like a incompressible fluid and permeability can be determined by using Darcy's law (Huo and Benson, 2015).

According to this, permeabilities are determined under stepwise changes of effective stress $\left(\sigma^{\prime}\right)$. Here, $\sigma^{\prime}$ is defined as the difference between applied confining pressure and pore pressure. In order to characterize stress dependency of the fractured sample comprehensively, changes in $\sigma^{\prime}$ represent a full loading-unloading cycle. Following this, $\sigma^{\prime}$ is increased stepwise from $0.7 \mathrm{MPa}(2.1,3.5,5.5,11.0 \mathrm{MPa})$ to $22.1 \mathrm{MPa}$ under loading conditions and, subsequently, are decreased by applying equivalent stress intervals.

Contemporaneously, the core holder is positioned in a medical X-ray CT scanner (General Electric Hi-Speed CT/I $\mathrm{X}$-ray computed tomography) to reveal "real-time" images of the sample for every stress stage. Scans were performed at an energy level of $120 \mathrm{keV}$, a tube current of $200 \mathrm{~mA}$ and a display field of view of $25 \mathrm{~cm}$. We use CT scans to obtain an $x-y$ resolution in the plane of $0.5 \times 0.5 \mathrm{~mm}^{2}$ and a slice thickness of $1 \mathrm{~mm}$ resulting in corresponding voxel dimensions. As a result of the CT scans each voxel is assigned to a specific CT number in Hounsfield units (HU). Furthermore, at each stress stage, multiple (five) scans are conducted and averaged afterwards, representing a practical method to reduce the random noise of CT scans by $50 \%$ as extensively discussed by Huo et al. (2016) and Pini et al. (2012). 


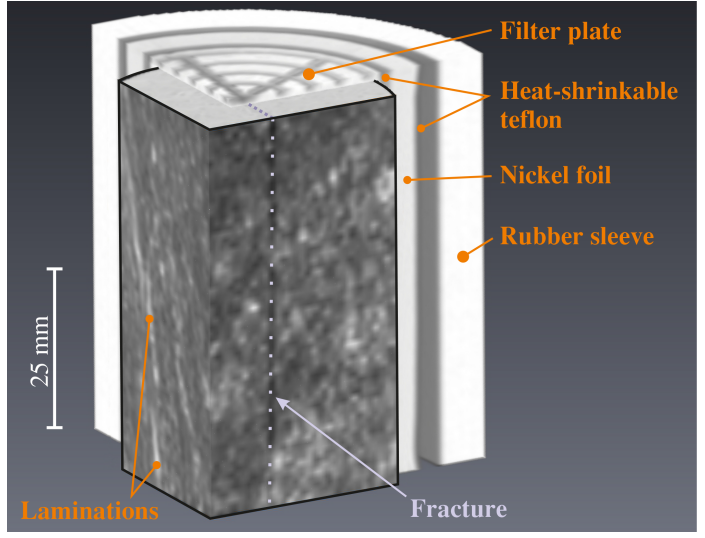

Figure 3. The computed tomography (CT) image of the rock sample with a rescaled voxel dimension $\left(0.25 \times 0.25 \times 0.25 \mathrm{~mm}^{3}\right)$. The upper filter plate, the units of the core holder and lamination of the sample are highlighted in orange. The fracture is indicated by a dotted purple line.

\subsection{Image processing}

The geometry of the model is based on the averaged, multiple CT scan revealing a cylindrical set with a total dimension of $256 \times 256 \times 68$ voxels that still contains the multilayer construction of the core holder as well as the filter plates of the fluid in- and outlet. Full processing is performed by using a customized MATLAB code. After reading the five data sets, every CT scan is resampled to an isotropic voxel size (one voxel of $0.5 \times 0.5 \times 1.0$ to 16 voxels of $0.25 \times 0.25 \times 0.25 \mathrm{~mm}^{3}$ ) required for a proper computation of the CFD program. Subsequently, the five scans are averaged to a single image (Fig. 3). In a further step, geometric information stored by single CT numbers of the (resampled) voxels are transformed voxel-wise to according geometric (local apertures) and hydraulic (local permeabilities) properties being essential for the flow simulations. The corresponding calibration approach is explained fully in the next paragraph. Finally, the core holder and filter plates are numerically cropped based on known core dimensions and obvious density contrasts, resulting in a final sample dimension of $194 \times 194 \times 258$ voxels. Note that marginal voxels of the sample are directly affected by the adjacent core holder so that the processed sample is slightly smaller than expected $(200 \times 200 \times 268$ voxels $)$.

Aperture calibration is based on the phenomena that the presence of (low-density) air or nitrogen, as used in this study, in a homogeneous rock matrix reduces CT numbers of voxels containing present voids. Considering a fractured homogeneous rock along a cross section perpendicular to the fracture plane, the resulting density contrasts can be perceived as a more or less pronounced anomaly depending on fracture width. Thus, an aperture calibration method (MA method) was developed by Johns et al. (1993) assuming that all X-ray attenuation is conserved in the CT image and that local apertures can be derived by integrating the available density anomalies. Dispersion of X-ray attenuation and partial volume effects can cause an expansion of the anomaly over adjacent voxels that gather this "missing attenuation" (Johns et al., 1993) and, in particular for larger fractures, represent a large portion of the entire anomaly. According to that, Johns et al. (1993) suggested a calibration-based linear relationship between aperture width and the integral of the full measured anomaly which was subsequently confirmed in several fracture aperture studies (Bertels et al., 2001; Heriawan and Koike, 2015; Huo and Benson, 2015; Keller, 1997; Ketcham et al., 2010; Van Geet and Swennen, 2001; Vandersteen et al., 2003; Weerakone and Wong, 2010) and physically established by Huo et al. (2016). Accordingly, the linearity between missing attenuation $\left(\mathrm{CT}_{\mathrm{MA}}\right)$ and fracture aperture $a$ can be simply described as

$\mathrm{CT}_{\mathrm{MA}}=C \cdot a$,

where the constant $C$ is given by the slope of the calibration line. Furthermore, $\mathrm{CT}_{\mathrm{MA}}$ is defined as

$\mathrm{CT}_{\mathrm{MA}}=\sum_{i=1}^{\mathrm{N}}\left(\mathrm{CT}_{\mathrm{mat}}-\mathrm{CT}_{i}\right)$,

where $\mathrm{CT}_{i}$ represents the $\mathrm{CT}$ number of the voxel along the cross section affected by the missing attenuation and $\mathrm{N}$ localizes the considered voxel. In this study, $\mathrm{CT}_{\text {mat }}$ represents an idealized global threshold value for the matrix material assuming a homogeneous rock matrix as also assigned in previous studies (Johns et al., 1993; Keller, 1997; Keller et al., 1999). Indeed, using a global $\mathrm{CT}_{\text {mat }}$ is a simplified assumption and provides additional errors particularly for heterogeneous rocks (Keller et al., 1997) but is sufficient for the intended straightforward purposes of this study. Usually, heterogenous rocks would require the usage of local $\mathrm{CT}_{\text {mat }}$ values (e.g., Huo et al., 2016) which would result in a large number of possible simulation results and would not improve the validity of the presented results. $\mathrm{CT}_{\text {mat }}$ is determined by averaging the single modes of all CT numbers at every pressure stage, assuming that the most frequent $\mathrm{CT}$ number dominates the matrix of the rock sample. Our results reveal a matrix number of $\mathrm{CT}_{\text {mat }}=1862 \mathrm{HU}$, which is in line with other CT-based sandstone studies (Akin and Kovscek, 2003; Huo et al., 2016; Vinegar et al., 1991).

Careful calibration with different spacers $(0.19,0.29,0.41$, $0.52 \mathrm{~mm}$ ) within the fracture indicates a slope of the linear calibration line of $5890 \pm 38.3 \mathrm{HU} \mathrm{mm}^{-1}$ (Fig. 4, after Huo et al., 2016). According to Eq. (1) and (2), apertures can therefore be calculated by

$a=\frac{\sum_{i=1}^{\mathrm{N}}\left(\mathrm{CT}_{\mathrm{mat}}-\mathrm{CT}_{i}\right)}{5890 \pm 38.3 \mathrm{HU} \mathrm{mm}^{-1}}$.

As a consequence, Eq. (3) (with $\mathrm{N}>1$ ) can be used to describe local apertures along the fracture; however, it is not 
practical to model the entire core sample. Typically, the MA in voxels adjacent to the voxel containing the fracture depends on rock type and aperture size (Huo et al., (2016)). Considering several cross sections through the fracture used here indicates that occasional local apertures affect $2-3$ voxels, where the vast majority ( $\geq 99 \%)$ of the attenuation is captured by the central voxel causing a local but marginal information loss. Hence, assuming that the main information about fracture aperture is stored in one voxel, we define $\mathrm{N}=1$, which also benefits the calculation of apertures for every single voxel of the core sample. However, it is worth mentioning that the applied calibration method would get more and more erroneous with increasing fracture widths. However, whether a fracture is large or not is also coupled to the CT resolution; thus, the voxel-wise calibration would cause artifactual apertures in the adjacent voxels actually representing the matrix and also would underestimate apertures in the voxels containing the fracture. In this study, most voxels containing the fracture range between 1700 and $1820 \mathrm{HU}$, suggesting that calculated (and summarized) apertures of each aperture cannot exceed $0.15 \mathrm{~mm}$ and most widely are significantly smaller than $0.1 \mathrm{~mm}$. This corresponds to Huo and Benson (2015), who determined mean apertures between 0.025 and $0.031 \mathrm{~mm}$. Negative apertures due to $\mathrm{CT}_{i}>\mathrm{CT}_{\text {mat }}$ as a result of the heterogeneity of the matrix or due to remaining image noise are defined as "zero apertures" with $a=0 \mathrm{~mm}$.

Although this strategy does not describe the basic intention of the common MA method, it provides a convenient solution to include data for the entire core and also enables integrations of regions with higher porosity within a homogenous matrix material where fluid inclusions should decrease $\mathrm{CT}_{\text {mat }}$. Hence, voxels representing sections of the matrix with significant porosity should reveal lower CT numbers $\left(\mathrm{CT}_{i}<\mathrm{CT}_{\mathrm{mat}}\right)$ so that these voxels, in simplified terms, are treated as equivalent apertures. These equivalent apertures represent the effective hydraulic diameter, which can be applied to characterize tube-like fluid flow in porous media (Debbas and Rumpf, 1966), and describes these tubes as rectangular ducts comprising the same area as the tubes (Janna, 2010).

Since simulating fluid flow does not work only with aperture information, each voxel has to be assigned to a potential hydraulic property. Assuming laminar flow and that fluid flow within the core is mainly controlled by fracture properties, the "cubic law" approach (Boussinesq, 1868; Snow, $1965)$ is chosen to derive appropriate local permeabilities $\left(K_{\mathrm{MA}}\right)$ based on the MSMA aperture calibration, which is defined as

$K_{\mathrm{MA}}=\frac{a^{2}}{12}$.

\subsection{Simulation}

Fluid flow within the processed CT scan image is simulated using the FlowDict module of the multidisciplinary commercial GeoDict ${ }^{\circledR}$ program package (Math2Market, Kaiserslautern, Germany), which has been developed to predict (microstructure-based) physical material properties (Pfrang et al., 2007). In the past, GeoDict was successfully applied to several studies with geoscientific background concerning fluid flow or particle tracking in fractured as well as porous media (Khan et al., 2012; Leu et al., 2014; Pudlo et al., 2014; Rücker et al., 2015; Schwarz and Enzmann, 2013). The utilization of the FlowDict module is based on three basic prerequisites: (1) a 3-D voxel-based image of a permeable object, (2) experimental parameters such as mass flow and flow direction and (3) an incompressible Newtonian fluid. Indeed, the used fluid $\left(\mathrm{N}_{2}\right)$ is actually a compressible fluid but can be treated as an incompressible fluid due to experimental boundary conditions (e.g., pore pressure, flow rates) as mentioned earlier. FlowDict only supports two simulation types: predicting the mean fluid velocity based on pressure drop boundary conditions and vice versa. Afterwards, entire sample permeability can be derived by applying Darcy's law (only for considering laminar flow).

In this study, fluid flow simulations are based on an explicit finite-volume method that solves the Navier-StokesBrinkman equation according to Iliev and Laptev (2004). The governing equation comprises both incompressible isothermal flow in pure fluid regions represented by the NavierStokes equation and flow in solid (matrix) regions defined by hydraulic properties represented by the Brinkman extension of Darcy's law (Iliev and Laptev, 2004):

$$
\begin{aligned}
& \underbrace{-\mu \Delta \boldsymbol{u}+(\rho \boldsymbol{u} \cdot \nabla) \boldsymbol{u}}_{\text {Navier-Stokes }}+\overbrace{\mu K_{x}^{-1} \cdot \boldsymbol{u}+\underbrace{\nabla P=0}}^{\text {Darcy's law }}, \\
& \nabla \cdot \boldsymbol{u}=0,
\end{aligned}
$$

where $\mu$ is the fluid viscosity, $\rho$ the fluid density, $P$ represents fluid pressure and $\boldsymbol{u}$ is the 3-D velocity vector. Furthermore, the reciprocal local permeability $K_{x}^{-1}$ represents locally assigned permeability based on the aperture calibration $(x=\mathrm{MA})$, in voxels representing the solid matrix $(x=$ solid $)$ and further materials such as filter materials $(x=$ filter). Equation (5) outlines the momentum conservation which contains viscous forces, an advective acceleration term, the Brinkman extension to Darcy's law and the applied pressure gradient. Concurrently, the continuity equation (Eq. 6) describing the conservation of mass has to be valid. In order to solve the pressure-velocity relationship, a guess-and-correct procedure represented by the SemiImplicit Method for Pressure-Linked Equation (SIMPLE) algorithm (Patankar and Spalding, 1972) is implemented.

Fluid flow is simulated parallel to the core axis for nitrogen at $50{ }^{\circ} \mathrm{C}$ with respective values for density $\left(1.2 \mathrm{~kg} \mathrm{~m}^{-3}\right)$ 


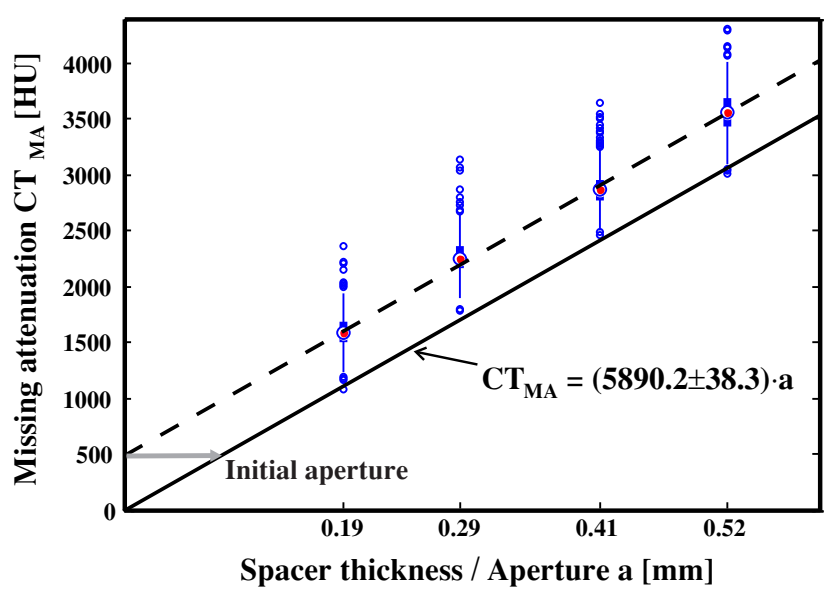

Figure 4. Calibration based on a total of 380 points at each spacer in order to apply the missing attenuation method. The circles with the red dot represent the medians for every spacer while smaller circles without dot are outliers. The thin and thick blue lines show $25 \%$ confidence intervals and $75 \%$, respectively. The dashed line corresponds to the regression line of all calibration points. The solid line corresponds to the adjusted regression line used for further aperture calculations by neglecting an apparent aperture $(0.08 \mathrm{~mm})$ caused by the fracture roughness (after Huo et al., 2016).

and viscosity $\left(1.9 \times 10^{-5} \mathrm{Ns} \mathrm{m}^{-2}\right)$. The simulations compute the velocity field for the given pressure drop using periodic boundary conditions on the computational box and Dirichlet boundary conditions for the pressure. Pressure drops for each stage of $\sigma^{\prime}$ are arbitrarily defined by measured values obtained for a flow rate of $16 \mathrm{~mL} \mathrm{~min}^{-1}$. $K_{\text {solid }}\left(5.92 \times 10^{-19} \mathrm{~m}^{2}\right)$ were obtained by MICP analysis (Sect. 2.1). In addition, in order to stabilize the simulation and to provide homogeneous in-/outflow as experimentally accomplished by filter plates, two artificial filter plates with $K_{\text {filter }}=1 \times 10^{-10} \mathrm{~m}^{2}$ are attached to the inlet and outlet according to the experimental setup (cf. Fig. 3). Indeed, hydraulic properties of these filter plates are also included into flow simulations and associated permeability calculations; however, affectations can be assumed to be negligible due to the proportionally small extent of the filter plates $(194 \times 194 \times 5$ voxels $)$ compared to the sample dimensions $(194 \times 194 \times 258$ voxels $)$.

Simulations are terminated by either reaching the accuracy criterion (ratio of current to former calculated permeability during iteration) of $1.5 \times 10^{-4}$ or exceeding $10^{6}$ iterations. Simulations are performed with a high-performance computer containing four Interlagos processors (64 cores) with 512 GB of total RAM. Dependent on available capacity (24 or 48 cores in this study) and aperture calibration, computation time of a single simulation ranges between 2 and $4 \mathrm{~h}$.

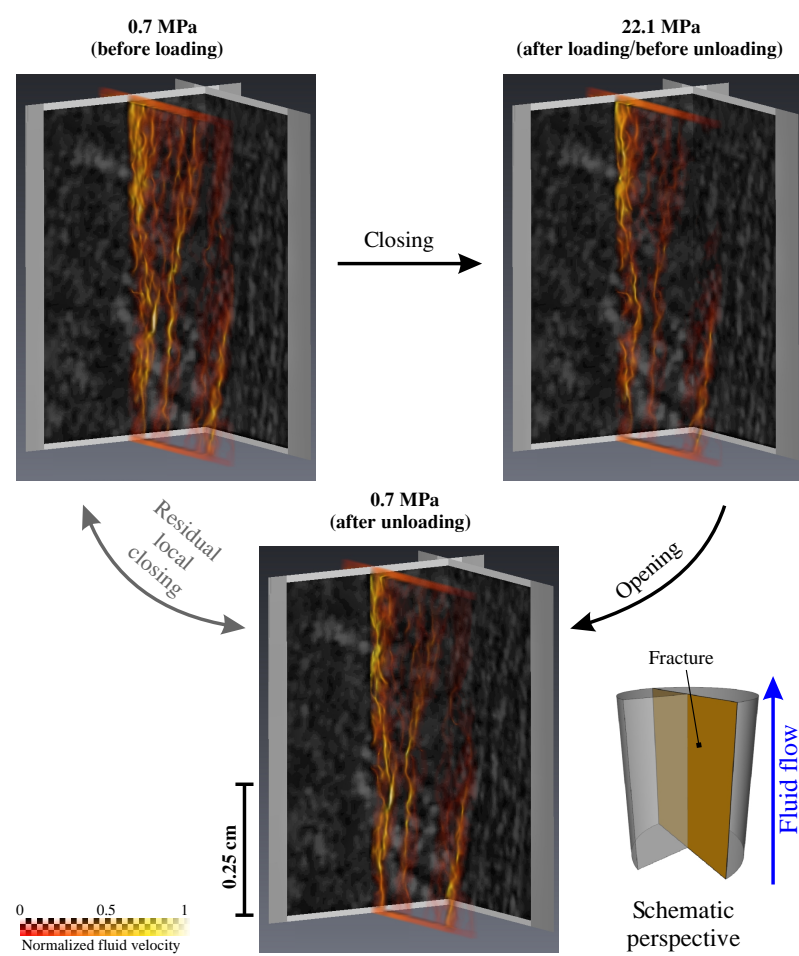

Figure 5. Changes in 3-D fluid flow only along the fracture plane due to closing during loading conditions (from 0.7 to $22.1 \mathrm{MPa}$ ) and due to reopening caused by unloading conditions (from 22.1 to $0.7 \mathrm{MPa}$ ) by applying forward modeling with an explicite finitevolume method solving the Navier-Stokes-Brinkman equation. Fluid flow is visualized by fluid velocity per voxel normalized by the maximum fluid velocity at the given pressure stage. Fluid velocity increases from red to yellow. Velocity fields of the initial and residual pressure stage $(0.7 \mathrm{MPa})$ indicate permanent local closings along the fracture. A schematic perspective is included for better 3-D orientation.

\section{Results and discussion}

\subsection{Simulation}

In this section, only the results of the simulations are discussed. For more detailed discussion and analysis on the experimental results, which particularly emphasize the hydraulic and geometric properties of the fracture as well as the applicability of empirical models, we refer to Huo and Benson (2015). However, some of their findings are discussed in the context of the quantitative and qualitative simulation results presented in this study.

Qualitative results mainly highlight the visualization of fluid flow simulations that can be used for flow path analysis. In contrast, quantitative results refer to fluid volumes for the different stress stages that can be directly validated by corresponding core-flooding experiments and are compared to the effectiveness of other simulation approaches. 
Visualizations of all simulation results indicate that principal fluid flow in the core is governed by a few preferential flow channels along the fracture plane that are partially interconnected (Fig. 5). Differentiating fluid flow simulations for single stresses shows the expected stepwise closure of the fracture and containing channels. This becomes clear for considering changes in local fluid flow with changes in effective stress. Applying loading conditions indicates a significant decrease in connectivity and local permeabilities within most parts of the fracture. In reverse, the same is observed for unloading conditions. This behavior is in line with an increasing (decreasing) percentage of contact areas and an increase (decrease) of smaller apertures due to loading (unloading) presented by Huo and Benson (2015). Furthermore, applying unloading conditions includes the re-increase of connectivity and permeability due to the opening of several channels and branches. However, some channels and especially branches remain closed or disconnected as a result of irreversible deformation (Fig. 5). Hence, it can be assumed that changes in fracture connectivity can be directly related to the strength of the present asperities (Huo and Benson, 2015; Pippan and Gumbsch, 2011). Accordingly, plastic deformation and brittle failures along asperity tips cause irreversible changes that are associated with the permanent local closings and constrictions as also depicted by Fig. 5. Elastic deformation can be assumed to be most widely reversible and facilitates local reopenings.

Furthermore, additionally enhanced fluid flow is observed in single parts within the matrix (Fig. 6). Comparing with the CT image (Fig. 3) indicates that this flow occurs along laminations containing darker matrix voxels with $\mathrm{CT}_{i}<\mathrm{CT}_{\text {mat }}$ according to Eq. (3). In homogeneous media $\mathrm{CT}_{\text {mat }}$ simply should represent the predominant mineral phase. In fact, the rather heterogenous sandstone in this study is dominated by quartz (detrital grains and cement) but is also enriched in feldspar. This feldspar component predominantly consists of plagioclase with minor alkali feldspars (Weissbrod and Sneh, 2002). Although there are compositional differences, quartz and plagioclase typically reveal similar and, compared to most other minerals, relatively low $\mathrm{CT}_{i}$ values (Ketcham, 2005; Tsuchiyama et al., 2005). Thus, the assumed $\mathrm{CT}_{\text {mat }}$ $(1862.6 \mathrm{HU})$ most widely can be ascribed to these dominant mineral phases. Hence, regions with significantly lower $\mathrm{CT}_{i}$ values are caused by significant porous regions. This porosity heterogeneity is also observed in thin sections (Huo et al., 2016, Huo and Benson, 2015). Nevertheless, the simulated overall matrix permeability can be assumed to be rather low, which is also clarified by carefully examining the propagation of the pressure fields corresponding to the predefined bulk matrix permeability of $10^{-19} \mathrm{~m}^{2}$. Concurrently, propagation of the pressure fields also reinforces the assumption that major fluid flow occurs along the fracture. Furthermore, comparing absolute changes in fluid flow (Fig. 6) due to loading between the lowest $(0.7 \mathrm{MPa})$ and the highest $(22.1 \mathrm{MPa})$ pressure stage indicates that most changes within the sam-
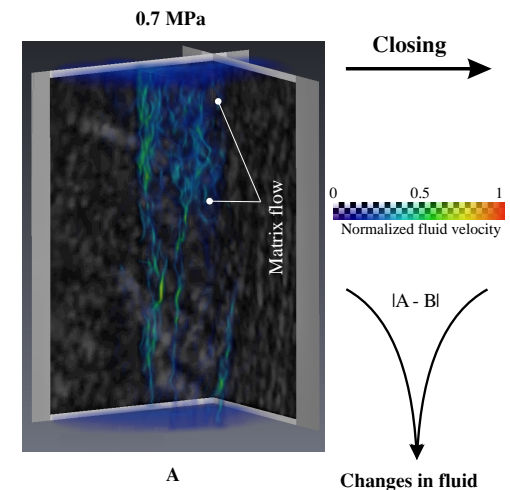

Changes in fluid

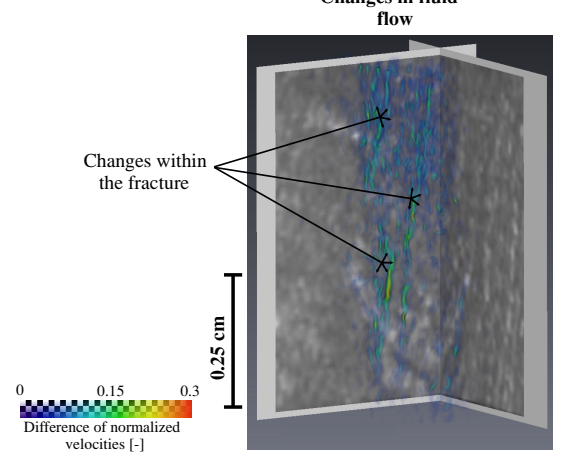

Figure 6. Changes in 3-D fluid flow sample due to closing (A and B) during loading conditions (from 0.7 to $22.1 \mathrm{MPa}$ ) by applying forward modeling with an EFV method to solve Navier-StokesBrinkman. Flow visualizations comprise fracture as well as matrix flow. Fluid flow is visualized by fluid velocity per voxel normalized by the maximum fluid velocity at the given pressure stage. Fluid velocity increases from purple to red. Absolute changes in fluid flow $(|\mathrm{A}-\mathrm{B}|)$ are shown in the lower part. Most changes occur within the fracture. Absolute changes increase from purple to red. A schematic perspective is included for better 3-D orientation.

ple occur along the fracture plane while the simulated matrix flow remains nearly equal. Unfortunately, core permeability is derived by solving the Navier-Stokes-Brinkman equation for the measured pressure drop over the entire sample (as stated in Sect. 2.4), which prevents the quantification of the matrix permeability. Due to the missing appropriate validation experiments and the negligible matrix flow, possible fracture-matrix interaction is not further discussed in this study and can be considered as uninfluential artifacts of the matrix material. Nevertheless, the MSMA method can provide a promising approach to simulate such issues, especially considering laminated sandstones, which were experimentally investigated in the past (Clavaud et al., 2008; Grader et al., 2013; Karpyn et al., 2009). Indeed, this method can be erroneous for heterogeneous rocks such as granite, but Watanabe et al. (2011) found that affectations of locally resulting non-real apertures in the matrix are marginal.

In contrast to qualitative analysis, quantitative results of the simulation significantly differ from expected results (Fig. 7a). Although there are significant deviations, quan- 

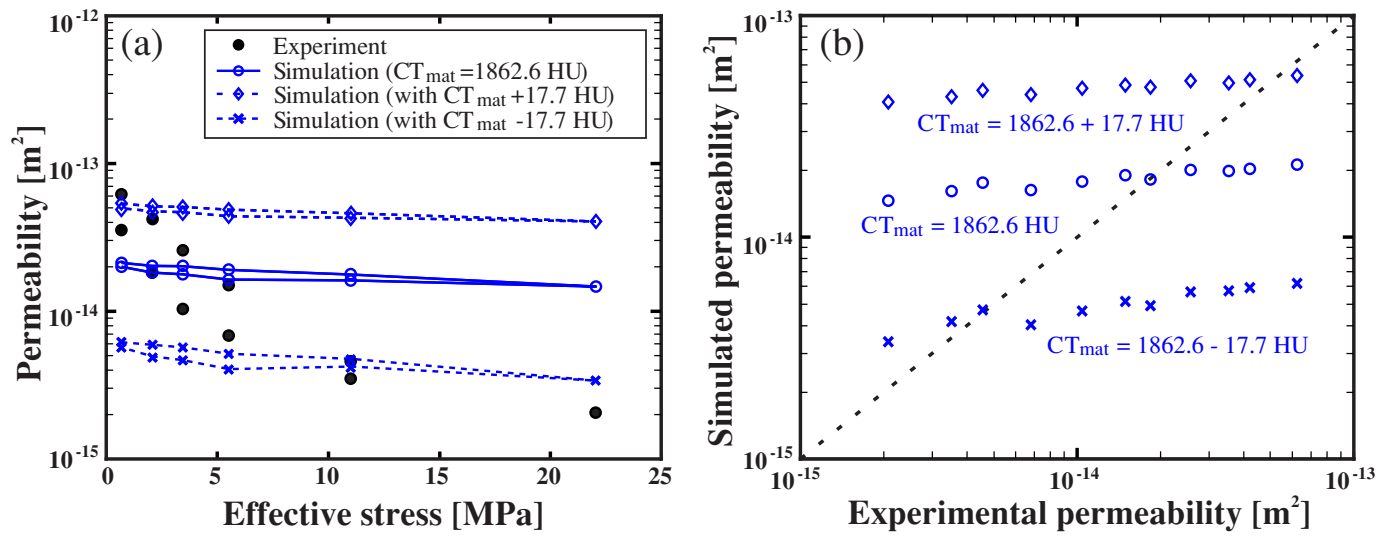

Figure 7. (a) Measured and simulated permeabilities of the entire core sample versus effective stress. Simulation results are obtained by forward modeling (cf. Eq. 3) and by changing $\mathrm{CT}_{\text {mat }}$ according to the mean standard deviation of the CT measurements (cf. Eq. 7) and (b) corresponding deviations between experimental and simulated permeabilities indicating a systematic error.

titative results exhibit several characteristics also observed in the experiment (Huo and Benson, 2015) such as (weakened) hysteretic behavior, discernible decreases of permeability with increasing pressure and subsequent reactivation of fluid paths under unloading conditions. A first simple (straightforward) simulation is based on an aperture calibration that applies a global CT number for the matrix material $\left(\mathrm{CT}_{\mathrm{mat}}=1862.6 \mathrm{HU}\right)$ as introduced in Sect. 2.3. Additionally, two further simulations are based on modified $\mathrm{CT}_{\text {mat }}$ values. For the latter, the standard deviation of the voxels is considered. Commonly, image quality of CT scans can be affected by random noise caused by imprecisions during CT image reconstruction (Huo et al., 2016; Pini et al., 2012) or by the reduction of X-ray intensity due to the presence of metal filters to reduce beam hardening (Ketcham and Carlson, 2001; Nakashima and Nakano, 2014; Watanabe et al., 2011). As a result of the induced noise, Huo et al. (2016) ascertained a mean standard deviation of $\pm 17.7 \mathrm{HU}$ for each of the voxels. Thus, two "worst-case" scenarios are considered by implementing the terms $\mathrm{CT}_{\text {mat }} \pm 17.7 \mathrm{HU}$ as input parameters for model calibration of these scenarios to account for uncertainties in $\mathrm{CT}_{\text {mat }}$.

Considering the simple modeling approach, the simulated permeabilities are in the range of minimum and maximum measured permeabilities. However, the permeabilities are clearly underestimated (up to a factor of 0.3) at lower $\sigma^{\prime}$ and significantly overestimated (up to a factor of 7.1) at higher $\sigma^{\prime}$. As a result, slopes of the stress-dependent permeability curve diminishes for lower $\sigma^{\prime}$ under loading as well as unloading conditions, which consequently contributes to a declined hysteresis area compared to experimental results. This reduction of hysteresis area indicates that intensity of fracture closing derived from CT images appears to be depressed. Possible explanations for this observation are discussed hereinafter.
Comparing the deviation between predicted and observed results indicates that there appears to be a systematic error affecting the simulation results (Fig. 7b). Of course, this could be caused by uncertainties of the pressure drop measurements during the experiment. However, permeabilities calculated by considering pressure drop uncertainties indicate deviation by a maximum factor of 1.2 and a minimum factor of 0.9 at the lowest loading stage (Huo and Benson, 2015). Most factors of other pressure stages are about 1.0 so that this uncertainty seems to be negligible. Counterchecking of the model input data and boundary conditions showed that the error of the simulation mainly relies on the aperture calibration. For that reason, we tested the sensitivity of the simulation focusing constants (slope and $\mathrm{CT}_{\mathrm{mat}}$ ) and shape of the calibration line.

Varying the slope (5980.2 $\mathrm{HU} \mathrm{mm}^{-1}$, according to Eq. 3) between \pm 1 and $5 \%$ hardly reveals any effect on the hysteresis except a very slight shift along the ordinate. This should be explained by very low apertures within the fracture, as represented by mean apertures between 0.025 and $0.031 \mathrm{~mm}$ as shown by Huo and Benson (2015), so that changes within the slope hardly affect apertures at the considered scale.

Furthermore, in order to be valid and as introduced in Sect. 2.3, the MSMA method requires a linearity of the calibration line as reinforced by a careful calibration according to Huo et al. (2016) who also physically derived the linear relationship which justifies the extrapolation of apertures as performed here.

An additional factor that can contribute a major part to the simulated deviations is represented by $\mathrm{CT}_{\text {mat }}$ describing an averaged threshold value for the matrix material. Being apparent from Fig. 3, there are significant material heterogeneities within the sample. While darker voxels (with $\mathrm{CT}_{i}<\mathrm{CT}_{\text {mat }}$ ) can be assumed to contain more porous regions as discussed above, there are also significant brighter voxels (with $\mathrm{CT}_{i}>\mathrm{CT}_{\text {mat }}$ ). These significantly higher $\mathrm{CT}$ (partially 
$\mathrm{CT}_{i}>1900 \mathrm{HU}$ ) values can be ascribed to the local accumulation of alkali feldspars, typically revealing much higher $\mathrm{CT}$ values (up to $100 \mathrm{HU}$ ) than quartz due to the high attenuation of potassium (Ikeda et al., 2000). Thus, locally present alkali feldspar in a voxel can cause a local underestimation or even closing of the calibrated local aperture according to Eq. (3), most likely making a significant contribution to the underestimation of permeabilities at lower pressures (cf. Fig. 7a).

Additionally, this local underestimation can be reinforced by an inappropriate choice of the threshold value $\mathrm{CT}_{\text {mat }}$, which also implies some uncertainties. Hence, we focus here on the sensitivity of the simulations caused by uncertainties in $\mathrm{CT}_{\text {mat }}$. Thus, $\mathrm{CT}_{\text {mat }}$ is varied by the uncertainties provided by random noise by including the averaged standard deviation $( \pm 17.7 \mathrm{HU})$. Adding the standard deviation $(+17.7 \mathrm{HU})$ to $\mathrm{CT}_{\text {mat }}$ indicates that simulated results at lower $\sigma^{\prime}$ are shifted towards the experimental data while results at higher $\sigma$ ' significantly overestimate the measurements. The opposite happens for $\mathrm{CT}_{\text {mat }}-17.7 \mathrm{HU}$, where simulations rather approximate measurements at higher $\sigma^{\prime}$ and strongly underestimate measurements at lower $\sigma^{\prime}$. According to Eq. (3) and Fig. 4 this is obvious since a higher $\mathrm{CT}_{\text {mat }}$ causes the calibration of larger apertures and, therefore, partially opens new flow channels by ascribing apertures that are zero for non-adjusted $\mathrm{CT}_{\text {mat }}$. Vice versa, non-adjusted channels are constricted or closed by slightly tighter apertures applying a lower $\mathrm{CT}_{\text {mat }}$. Hence, the simulation results are highly sensitive to changes in $\mathrm{CT}_{\text {mat }}$. Modifying $\mathrm{CT}_{\text {mat }}$ just by $+17.7 \mathrm{HU}$ increases simulated permeabilities up to a mean factor of $2.6 \pm 0.1$. In contrast, reducing $\mathrm{CT}_{\text {mat }}$ by $-17.7 \mathrm{HU}$ diminishes simulation results up to a mean factor of $0.3 \pm 0.02$. Hence, the simulated results that contain the standard deviation of the CT scan are able to cover the full range of experimental values. However, the latter also clearly demonstrate that the used simulation is unable to explicitly reproduce the measured permeability hysteresis. Indeed, the simulations can be fitted by varying $\mathrm{CT}_{\text {mat }}$ within the mentioned range but the compression and resulting strain on the finegrained sample as well as the evaluation of the single images do not endorse such a proposal.

A further reasonable explanation for the deviations of the simple simulation approach (with $\mathrm{CT}_{\text {mat }}=1862.6 \mathrm{HU}$ ) from the experimental hysteresis is the presence of potential subgrid-scale features. This means that variations in the fracture topography most likely are significantly below the CT resolution $\left(0.5 \times 0.5 \times 1.0 \mathrm{~mm}^{3}\right)$ so that the actual roughness cannot be captured accurately. Thus, in addition to compositionally caused underestimation of local apertures, the resolution-caused generalization of these features per voxel underestimates experimental permeabilities at lower stresses due to a reduction in actual (sub-grid-scale) connectivity. While at higher stresses the permeability is overestimated by suggesting generalized flow paths. Actually, it can be assumed that there is a significant amount of contact areas within the single voxels causing sub-scale inhibition of fluid flow or connectivity. Therefore, the transferred fracture roughness represents only an approximation of a finer and more complex flow pattern within the smooth fracture where connectivity and tortuosity can be assumed to play a more significant role.

\subsection{Comparison}

As stated above (Table 1), several authors have published stress-dependent fluid flow studies based on variously derived fracture geometries and numerical approaches. Until now, medical CT data and, thus, most untreated input data were solely applied by Watanabe et al. $(2011 ; 2013)$. In their first study (Watanbe et al., 2011), the authors used an aluminum core holder for core-flooding experiments on tensile single-fractured (SF for single fracture) and naturally doublefractured (MF for multiple fractures) granites. In Fig. 8a simulated permeabilities resulting from their approach are compared to the results of this study (only loading conditions are shown). As one might expect, measured permeabilities of the four core-flooding experiments decrease with increasing $\sigma^{\prime}$. Although both rock types, Zenifim sandstone and granite, reveal similar matrix permeabilities $\left(10^{-18}\right.$ to $\left.10^{-19} \mathrm{~m}^{2}\right)$, fluid flow experiments with the fractured sandstone obtain higher permeabilities (between $10^{-14}$ and $10^{-15} \mathrm{~m}^{2}$ ) than granite experiments (between $10^{-15}$ and $10^{-17} \mathrm{~m}^{2}$ ). Typically, mean apertures of mated tensile fractures in Inada granite should decrease from 0.071 to $0.065 \mathrm{~mm}$, applying loading from 10 to $100 \mathrm{MPa}$ (Watanabe et al., 2008). Mean apertures of the sandstone sample are significantly lower and range between 0.031 and $0.024 \mathrm{~mm}$ (Huo and Benson, 2015). Nevertheless, with increasing stresses, hydraulic apertures of the granite fracture decrease from 0.009 to $0.003 \mathrm{~mm}$ (Watanabe et al., 2008) while hydraulic apertures of the sandstone fracture decrease from approximately 0.030 to $0.005 \mathrm{~mm}$ (Huo and Benson, 2015). These significant hydraulic differences of the samples appear to be caused by higher tortuosity as described by Tsang (1984) due to a higher roughness of the tensile granite fractures as compared with the smooth sandstone fracture. In addition, this dependency between fluid flow and tortuosity is reinforced by considering CFD-based flow visualizations of the granite sample, indicating a highly tortuous network of flow channels along the fracture (Watanabe et al., 2011).

In order to clarify the effectiveness of the compared simulation approaches, discrepancies between simulated and experimental permeabilities of each sample are plotted as factors against the normalized effective stress in Fig. 8a. It can be seen that simulated permeabilities of the SF sample are 5 (at $5 \mathrm{MPa}$ ) to 116 times (at $50 \mathrm{MPa}$ ) higher than predicted by the experimental data, while simulations based on the MF sample overestimate experimental results by a factor of 30 (at $5 \mathrm{MPa}$ ) and 106 (at $50 \mathrm{MPa}$ ). Overestimations are supposed to be primarily caused by image noise due to the core holder causing "non-zero apertures" and, in consequence, extended 


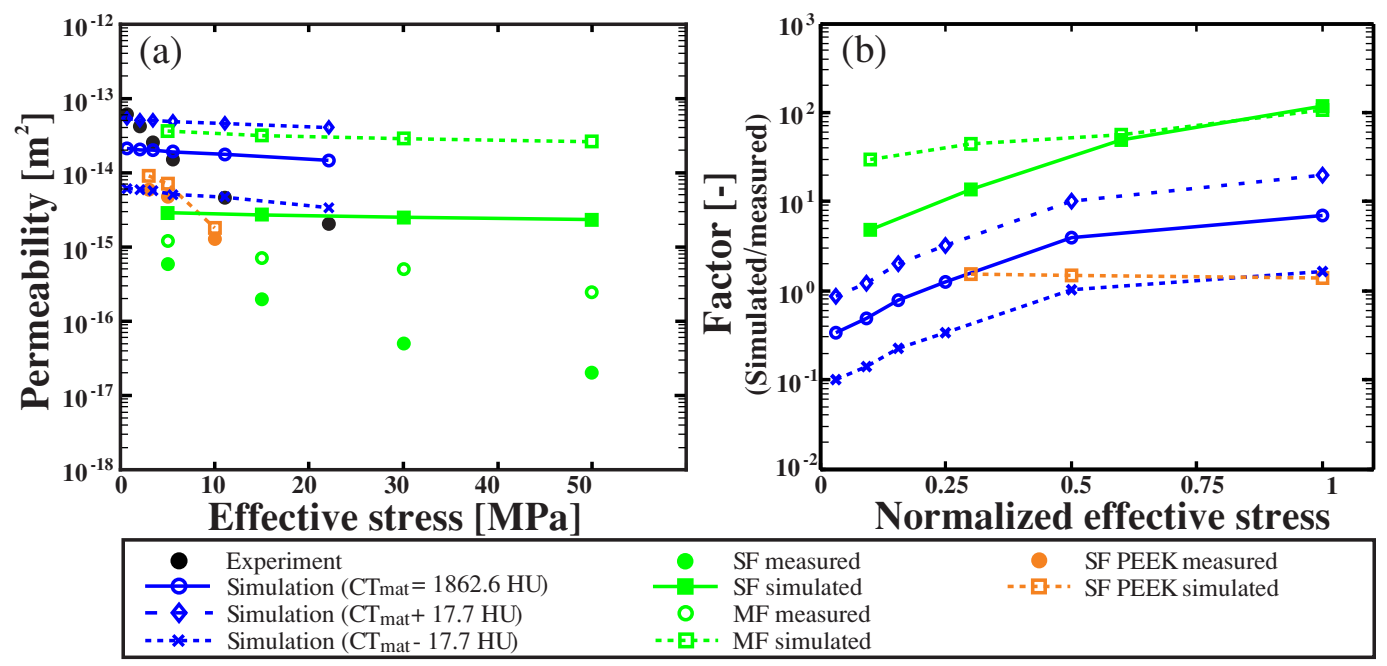

Figure 8. Comparison of experimental and simulated data of the sandstone sample with results obtained from the literature using CT technology to realize simulations (Watanabe et al., 2011, 2013). Literature data are based on a three granite core samples with a single tensile fracture (SF), multiple, natural fractures (MF) and a single tensile fracture measured by using an improved core holder (SF PEEK). Furthermore, the effectiveness of the simulations is shown in (b) as factors, describing the discrepancy between each simulated and corresponding experimental permeability value, versus the normalized effective stresses depending on the highest stress stage applied during the associated experiment.

flow paths within the fracture and the matrix (Watanabe et al., 2011). Considering the three simulation scenarios conducted within the scope of this study, experimental permeabilities are over- or underestimated ranging between a minimum factor of 0.1 and a maximum factor of 20. Considering only the simple simulation approach (with $\mathrm{CT}_{\mathrm{mat}}=1862.6 \mathrm{HU}$ ) numerical results show a maximum overestimation by a factor of 7.1 and a minimum underestimation by a factor of 0.3 . Accordingly, the MSMA method appears to reveal slightly better simulation results than Watanabe et al. (2011), although the considered fracture is significantly smaller which indicates an effective noise reduction by applying multiple scans. However, in a subsequent study Watanabe et al. (2013) improved their approach (Fig. 8a) with an adjusted experimental setup on a granite containing a single tensile fracture (SF PEEK) by using a carbon fiber reinforced polyether ether ketone (CFR PEEK) core holder. Applying the PEEK core holder significantly reduced the image noise and revealed nearly concurrent experimental and simulated results.

Accordingly, the introduced MSMA method represents a further approximating step for successful CFD simulations but also exposes current limitations. Although applying the method with a global $\mathrm{CT}_{\text {mat }}$ affirm a loss in accuracy as predicted by Keller (1997) for smooth fractures $(<35 \mu \mathrm{m})$, simulation results still are valuable to approximate actual permeabilities in such fractures. Indeed, compositional heterogeneities provide inaccuracies as also predicted by Keller (1997) but are not so dominant that they cause a complete loss of information, as indicated by the kinematics of several reproducible flow channels. Neverthe- less, inaccuracy is provided not only by compositional heterogeneities but also by sub-grid-scale features, particularly regarding higher confining pressure and, thus, closing local apertures.

Focussing on our own experiences and including the pioneering research by Watanabe et al. (2011 and 2013), we provide the following recommendations for future medical CT-based fracture flow studies.

The determination of more detailed pore data of the matrix, especially when considering heterogeneous porous rocks, is done by introducing additional MICP measurements and technologies such as micro-CT, environmental scanning electron microscopy (ESEM) or nuclear magnetic resonance (NMR) spectrometry. Additionally, an upscaling of micro$\mathrm{CT}$ data to core scale and coupling this matrix with a medical CT-based aperture distribution of the fracture would provide more realistic pore-geometry data for simulating fracturematrix flow interaction.

Before fracture flow experiments start, some "blank tests" should be considered. Core-flooding experiments of the unfractured core sample can provide additional information about the actual hydraulic properties of the matrix. Furthermore, scans of the unstressed fractured sample with a PEEK core holder (to reduce the beam hardening effect) can be used to detect image noise, which is caused by the metal core holder used in common core-flooding experiments as presented by Watanabe et al. (2013). In this study, image noise cannot be explicitly assigned to the core holder and is most widely due to the imperfections of the $\mathrm{CT}$ image reconstruction as also stated for equivalent experimental setups (Huo 
et al., 2016; Pini et al., 2012). However, an additional affectation due to the core holder cannot be excluded so that a "blank test" would be very beneficial. Since both mentioned noise sources create random noise in the CT image both quality improvement methods, the PEEK core holder and the multiple scan method, should be tested for their effectiveness. Ideally, both methods should be combined to diminish affectations of both possible noise sources. However, PEEK core holder technology was only successfully applied for maximum confining pressure between 36 and $50 \mathrm{MPa}$ at room temperatures $\left(23^{\circ} \mathrm{C}\right.$; Ito et al., 2013; Watanabe et al., 2013) and, thus, is a useful option for experiments focussing on similar conditions. Typically, the strength of PEEK strongly depends on temperature (Searle and Pfeiffer, 1985) and the chemical composition of the fluid used for the experiment (Pritchard, 1994) and, thus, appears to be challenging for experiments that simulate reservoir conditions or processes in the deeper Earth's crust. Additionally, this study is based on low voxel resolutions $\left(0.5 \times 0.5 \times 1.0 \mathrm{~mm}^{3}\right)$ generalizing the area, which is covered by the voxel, to a single aperture value. Thus, high-resolution fracture measurements such as laser-scanning or profilometer measurements should be helpful to detect the effect of generalized fracture morphologies within the voxel scale by comparison with unstressed "blank test" data.

Typically the common MA method is used to determine apertures only perpendicular to the fracture plane, rather favoring 2-D aperture distributions. Despite that, the MSMA indicates a good transferability of present apertures to a 3$\mathrm{D}$ problem favored by the tightness of the studied fracture with mean apertures between 0.031 and $0.024 \mathrm{~mm}$, where the fracture-caused anomaly predominantly affects the voxel containing the fracture. However, with increasing fracture width it becomes more likely that the anomaly also affects adjacent voxels and the aperture calibration becomes invalid. Thus, the applicability of the introduced method should be validated for additional scenarios: (1) for different fracture widths where apertures must be smaller than the $x-y$ resolution of the CT scan; (2) for different fracture types such as smooth and rough fractures or tensile and shear fractures; (3) for different materials highlighting the influence of different heterogeneities caused by the mineralogical composition or porosity; (4) for different applicable $x-y$ resolutions provided by medical CT scanners (e.g., $0.2 \times 0.2$ or $0.3 \times 0.3 \mathrm{~mm}^{2}$ ). However, most of the suggested scenarios depend on each other and should be critically considered. In addition, a similar procedure is recommended for the $\mathrm{PH}$ method used by Watanabe et al. (2011) to underline the scope of applications and limitations of both methods.

In this study, aperture calibration is based on the general assumption of a linear relationship between MA and aperture width (e.g., Bertels et al., 2001; Keller, 1997; Van Geet and Swennen, 2001) and, thus, on a crude spacer calibration (with four spacers $\geq 0.2 \mathrm{~mm}$ ). However, Mazumder et al. (2006) found a significant nonlinear relationship by ap- plying an optimized MA approach to minimize affectations due to heterogeneities of their coal sample. They found that the slope of the line significantly increases with decreasing apertures $(<0.25 \mathrm{~mm})$. Therefore, future studies should focus on a more accurate spacer calibration, particularly with spacers $<0.1 \mathrm{~mm}$, which corresponds to many apertures under confining pressure.

In order to validate qualitative fluid flow, new contrast agents should be introduced. Conventionally used iodine was shown to cause beam hardening effects that exacerbate the interpretation of flow paths within the fracture (Watanabe et al., 2011). Meanwhile, sodium polytungstate $\left(\mathrm{Na}_{6} \mathrm{H}_{2} \mathrm{~W}_{12} \mathrm{O}_{40}\right)$ was proposed as a promising contrast agent for hydrological CT experiments by significantly reducing the undesirable beam hardening effect (Nakashima, 2013; Nakashima and Nakano, 2014). Alternatively, further technologies such as positron emission tomography could be applied (Fernø et al., 2015; Kulenkampff et al., 2008).

\section{Conclusions}

A alternative method to simulate fluid flow in a fractured porous core sample under loading and unloading conditions based on medical CT measurements was introduced. Simulation results reveal qualitative plausibility but also reveal shortcomings considering quantitative results. Generally, the proposed method is able to approximate experimentally derived permeability data even in smooth fractures $(<35 \mu \mathrm{m})$; however, it merely indicates the stress dependency of fracture permeability.

Qualitative results reveal satisfactory accordance with the well-established flow channeling approach, indicating that major flow is governed by several preferential flow paths along the fracture with less pronounced tortuosity. The simulations reproduce temporal and permanent closing of some flow channels due to increasing effective stress, causing significant changes in connectivity and associated permeability.

Despite the quantitative deviations, the simulated permeabilities indicate stress dependency of the sample represented by a slight decrease in permeability with increasing effective stress and even imply hysteretic behavior. Besides minor calibration errors, the deviations are mainly caused by compositional heterogeneities of the matrix material and resolutioncaused limitations. The former facilitates underestimation of local hydraulic properties, while the latter prevents an accurate capturing of sub-grid-scale features. Both error sources affect the reproduction of actual connectivity playing an important role in smooth fractures. Furthermore, the simulation is very sensitive to the choice of an adequate threshold value $\mathrm{CT}_{\text {mat }}$ (1862.6 HU in this study). Small deviations from the ideal $\mathrm{CT}_{\text {mat }}( \pm 17.7 \mathrm{HU}$ in this study) can cause enormous changes in simulated permeability by up to a factor of 2.6 \pm 0.1 . Thus, $\mathrm{CT}_{\text {mat }}$ has to be defined with caution and 
can cause additional problems for rocks with significant mineralogical heterogeneities.

Nevertheless, the comparison with an analogous CT-based CFD study by Watanabe et al. (2011) reveals that the introduced MSMA approach can be a valuable method to analyze quantitative and qualitative fracture flow. Considering the aforementioned comparative study a list of recommendations for future research is compiled, including a systematic investigation concerning different experimental and model setups, rock types, fracture modes as well as validation techniques.

\section{Data availability}

Since the size of the underlying data is too large for an upload, the authors encourage interested readers to contact the co-authors. Raw CT data can be obtained from Da Huo (dhuosu@gmail.com). Processed CT data and simulation results (e.g., flow and pressure patterns) are stored on a server at the University of Mainz (Contact: enzmann@uni-mainz.de)

Acknowledgements. This study was mainly carried out within the framework of the Helmholtz Association of German Research Centres (HGF) portfolio project "Geoenergy" and is part of the comprised reservoir engineering cluster. In addition, we acknowledge the postdoctoral grant to Jens-Oliver Schwarz, which was funded within the framework of DGMK (German Society for Petroleum and Coal Science and Technology) research project 718 "Mineral Vein Dynamics Modelling". The latter is funded by the companies ExxonMobil Production Deutschland $\mathrm{GmbH}$, ENGIE E\&P Deutschland GmbH, DEA Deutsche Erdoel AG and Wintershall Holding $\mathrm{GmbH}$, within the basic research program of the WEG Wirtschaftsverband Erdöl- und Erdgasgewinnung e.V. The authors also want to thank Rani Calvo from the Geological Survey of Israel for providing the Zenifim sandstone sample used in this study. In particular, we thank Math2Market for providing the GeoDict software package for fluid flow simulations. We acknowledge support by Deutsche Forschungsgemeinschaft and Open Access Publishing Fund of Karlsruhe Institute of Technology. Last, but not least, we thank the anonymous referees for their constructive comments and valuable hints.

The article processing charges for this open-access

publication were covered by a Research

Centre of the Helmholtz Association.

Edited by: M. Halisch

Reviewed by: two anonymous referees

\section{References}

Akin, S. and Kovscek, A. R.: Computed tomography in petroleum engineering research, Geological Society, London, Special Publications, 215, 23-38, doi:10.1144/gsl.sp.2003.215.01.03, 2003.
Al-Yaarubi, A. H., Pain, C. C., Grattoni, C. A., and Zimmerman, R. W.: Navier-Stokes simulations of fluid flow through a rock fracture, in: Proceedings of the 2nd International Symposium on Dynamics of Fluids and Transport in Fractured Rock, edited by: Faybishenko, B. and Witherspoon, P. A., American Geophysical Union, 201-205, 2005.

Bernabe, Y.: The effective pressure law for permeability in Chelmsford granite and Barre granite, Int. J. Rock Mech. Min., 23, $267-$ 275, doi:10.1016/0148-9062(86)90972-1, 1986.

Bertels, S. P., DiCarlo, D. A., and Blunt, M. J.: Measurement of aperture distribution, capillary pressure, relative permeability, and in situ saturation in a rock fracture using computed tomography scanning, Water Resour. Res., 37, 649-662, doi:10.1029/2000wr900316, 2001.

Boussinesq, J.: Mémoire sur l'influence des Frottements dans les Mouvements Réguliers des Fluids, Journal de Mathématiques Pures et Appliquées, 2, 377-424, 1868.

Brush, D. J. and Thomson, N. R.: Fluid flow in synthetic rough-walled fractures: Navier-Stokes, Stokes, and local cubic law simulations, Water Resour. Res., 39, 1085 , doi:10.1029/2002wr001346, 2003.

Clavaud, J.-B., Maineult, A., Zamora, M., Rasolofosaon, P., and Schlitter, C.: Permeability anisotropy and its relations with porous medium structure, J. Geophys. Res.-Sol. Ea., 113, B01202, doi:10.1029/2007jb005004, 2008.

Crandall, D., Bromhal, G., and Karpyn, Z. T.: Numerical simulations examining the relationship between wall-roughness and fluid flow in rock fractures, Int. J. Rock Mech. Min., 47, 784796, doi:10.1016/j.ijrmms.2010.03.015, 2010.

Debbas, S. and Rumpf, H.: On the randomness of beds packed with spheres or irregular shaped particles, Chem. Eng. Sci., 21, 583608, doi:10.1016/0009-2509(66)85072-8, 1966.

Dicman, A., Putra, E., and Schechter, D. S.: Modeling fluid flow through single fractures using experimental, stochastic and simulation approaches, SPE/DOE Symposium on Improved Oil Recovery, Tulsa, Oklahoma, 17-21 April, 2004.

Feng, X.-T., Chen, S., and Zhou, H.: Real-time computerized tomography (CT) experiments on sandstone damage evolution during triaxial compression with chemical corrosion, Int. J. Rock Mech. Min., 41, 181-192, doi:10.1016/S1365-1609(03)00059-5, 2004.

Fern $\varnothing$, M. A., Gauteplass, J., Hauge, L. P., Abell, G. E., Adamsen, T. C. H., and Graue, A.: Combined positron emission tomography and computed tomography to visualize and quantify fluid flow in sedimentary rocks, Water Resour. Res., 51, 7811-7819, doi:10.1002/2015wr017130, 2015.

Gale, J.: Assessing the permeability characteristics of fractured rock, Geological Society of America Special Papers, 189, 163182, doi:10.1130/SPE189-p163, 1982.

Gangi, A. F.: Variation of whole and fractured porous rock permeability with confining pressure, Int. J. Rock Mech. Min., 15, 249 257, doi:10.1016/0148-9062(78)90957-9, 1978.

Ge, X., Ren, J., Pu, Y., Ma, W., and Zhu, Y.: Real-in time CT test of the rock meso-damage propagation law, Sci. China Ser. ETechnol. Sci., 44, 328-336, doi:10.1007/bf02916710, 2001.

Grader, A. S., Balzarini, M., Radaelli, F., Capasso, G., and Pellegrino, A.: Fracture-matrix flow: Quantification and visualization using X-Ray computerized tomography, in: Dynamics of Fluids in Fractured Rock (Geophysical Monograph Series 162), edited 
by: Faybishenko, B., Witherspoon, P. A., and Gale, J. E., American Geophysical Union, Washington, D.C., 157-168, 2013.

Heriawan, M. N. and Koike, K.: Coal quality related to microfractures identified by CT image analysis, Int. J. Coal Geol., 140, 97-110, doi:10.1016/j.coal.2015.02.001, 2015.

Huber, F., Enzmann, F., Wenka, A., Bouby, M., Dentz, M., and Schäfer, T.: Natural micro-scale heterogeneity induced solute and nanoparticle retardation in fractured crystalline rock, J. Contamin. Hydrol., 133, 40-52, doi:10.1016/j.jconhyd.2012.03.004, 2012.

Huo, D. and Benson, S. M.: An experimental investigation of stressdependent permeability and permeability hysteresis behavior in rock fractures, in: Dynamics of Fluids and Transport in Complex Fractured-Porous Systems (Geophysical Monograph Series 210), edited by: Faybishenko, B., Benson, S. M., and Gale, J. E., John Wiley \& Sons, Inc, Hoboken, NJ, 99-114, 2015.

Huo, D., Pini, R., and Benson, S.: A calibration-free approach for measuring fracture aperture distributions using X-ray computed tomography, Geosphere, 12, 558-571, doi:10.1130/GES01175.1, 2016.

Ikeda, S., Nakano, T., and Nakashima, Y.: Three-dimensional study on the interconnection and shape of crystals in a graphic granite by X-ray CT and image analysis, Mineralogical Magazine, 64, 945-959, doi:10.1180/002646100549760, 2000.

Iliev, O. and Laptev, V.: On numerical simulation of flow through oil filters, Comput. Visual Sci., 6, 139-146, doi:10.1007/s00791003-0118-8, 2004.

Indraratna, B., Kumara, C., Zhu, S.-P., and Sloan, S.: Mathematical modeling and experimental verification of fluid flow through deformable rough rock joints, Int. J. Geomech., 15, 04014065, doi:10.1061/(ASCE)GM.1943-5622.0000413, 2015.

Ito, H., Kato, K., Ochi, Y., Hosokawa, N., Watanabe, N., Mino, Y., and Tsuchiya, Y.: Fracture flow models of core samples by X-ray CT under pressure and numerical simulation, Proceedings of the 11th SEGJ International Symposium, Yokohama, Japan, 18-21 November 2013, 2013.

Janna, W. S.: Introduction to fluid mechanics, Boca Raton [etc.]: CRC Press, Taylor \& Francis Group, 2010.

Johns, R. A., Steude, J. S., Castanier, L. M., and Roberts, P. V.: Nondestructive measurements of fracture aperture in crystalline rock cores using X ray computed tomography, J. Geophys. Res.Sol. Ea., 98, 1889-1900, doi:10.1029/92jb02298, 1993.

Karpyn, Z. T., Alajmi, A., Radaelli, F., Halleck, P. M., and Grader, A. S.: X-ray CT and hydraulic evidence for a relationship between fracture conductivity and adjacent matrix porosity, Eng. Geol., 103, 139-145, doi:10.1016/j.enggeo.2008.06.017, 2009.

Keller, A. A.: High resolution cat imaging of fractures in consolidated materials, Int. J. Rock Mech. Min., 34, 155.e151155.e116, doi:10.1016/S1365-1609(97)00181-0, 1997.

Keller, A. A., Roberts, P. V., and Blunt, M. J.: Effect of fracture aperture variations on the dispersion of contaminants, Water Resour. Res., 35, 55-63, doi:10.1029/1998wr900041, 1999.

Ketcham, R. A.: Three-dimensional grain fabric measurements using high-resolution X-ray computed tomography, J. Struct. Geol., 27, 1217-1228, doi:10.1016/j.jsg.2005.02.006, 2005.

Ketcham, R. A.: Accurate three-dimensional measurements of features in geological materials from X-ray computed tomography data, in: Advances in X-ray Tomography for Geomaterials, edited by: Desrues, J., Viggiani, G., and Besuelle, P., ISTE Ltd., London, UK, 143-148, 2010.

Ketcham, R. A. and Carlson, W. D.: Acquisition, optimization and interpretation of X-ray computed tomographic imagery: applications to the geosciences, Comput. Geosci., 27, 381-400, doi:10.1016/S0098-3004(00)00116-3, 2001.

Ketcham, R. A., Slottke, D. T., and Sharp Jr, J. M.: Threedimensional measurement of fractures in heterogeneous materials using high-resolution X-ray computed tomography, Geosphere, 6, 498-514, doi:10.1130/ges00552.1, 2010.

Khan, F., Enzmann, F., Kersten, M., Wiegmann, A., and Steiner, K.: 3-D simulation of the permeability tensor in a soil aggregate on basis of nanotomographic imaging and LBE solver, J. Soils Sediments, 12, 86-96, doi:10.1007/s11368-011-0435-3, 2012.

Kim, I., Lindquist, W., and Durham, W.: Fracture flow simulation using a finite-difference lattice Boltzmann method, Phys. Rev. E, 67, 046708, doi:10.1103/PhysRevE.67.046708, 2003.

Konzuk, J. and Kueper, B. H.: A study on the use of cubic-law based models for simulating flow through discrete rough-walled fractures, Proceedings of Fractured Rock Aquifers Conference, Denver, CO, March 13-15 2002, 2002.

Konzuk, J. S. and Kueper, B. H.: Evaluation of cubic law based models describing single-phase flow through a rough-walled fracture, Water Resour. Res., 40, W02402, doi:10.1029/2003wr002356, 2004.

Koyama, T., Neretnieks, I., and Jing, L.: A numerical study on differences in using Navier-Stokes and Reynolds equations for modeling the fluid flow and particle transport in single rock fractures with shear, Int. J. Rock Mech. Min., 45, 1082-1101, doi:10.1016/j.ijrmms.2007.11.006, 2008.

Kranz, R. L., Frankel, A. D., Engelder, T., and Scholz, C. H.: The permeability of whole and jointed Barre Granite, Int. J. Rock Mech. Min., 16, 225-234, doi:10.1016/0148-9062(79)91197-5, 1979.

Krevor, S. C. M., Pini, R., Zuo, L., and Benson, S. M.: Relative permeability and trapping of $\mathrm{CO}_{2}$ and water in sandstone rocks at reservoir conditions, Water Resour. Res., 48, W02532, doi:10.1029/2011wr010859, 2012.

Kulenkampff, J., Gründig, M., Richter, M., and Enzmann, F.: Evaluation of positron-emission-tomography for visualisation of migration processes in geomaterials, Physics and Chemistry of the Earth, Parts A/B/C, 33, 937-942, doi:10.1016/j.pce.2008.05.005, 2008.

Landry, C. J. and Karpyn, Z. T.: Single-phase lattice Boltzmann simulations of pore-scale flow in fractured permeable media, Int. J. Oil Gas Coal Technol., 5, 182-206, doi:10.1504/IJOGCT.2012.046320, 2012.

Lenoir, N., Bornert, M., Desrues, J., Bésuelle, P., and Viggiani, G.: Volumetric digital image correlation applied to Xray microtomography images from triaxial compression tests on argillaceous rock, Strain, 43, 193-205, doi:10.1111/j.14751305.2007.00348.x, 2007.

Leu, L., Berg, S., Enzmann, F., Armstrong, R. T., and Kersten, M.: Fast X-ray micro-tomography of multiphase flow in Berea Sandstone: A sensitivity study on image processing, Transp. Porous. Med., 105, 451-469, doi:10.1007/s11242-014-0378-4, 2014.

Liu, W., Li, Y., and Wang, B.: Gas permeability of fractured sandstone/coal samples under variable confining pressure, Transp. 
Porous. Med., 83, 333-347, doi:10.1007/s11242-009-9444-8, 2010.

Madadi, M. and Sahimi, M.: Lattice Boltzmann simulation of fluid flow in fracture networks with rough, self-affine surfaces, Phys. Rev. E., 67, 026309, doi:10.1103/PhysRevE.67.026309, 2003.

Mazumder, S., Wolf, K. H. A. A., Elewaut, K., and Ephraim, R.: Application of X-ray computed tomography for analyzing cleat spacing and cleat aperture in coal samples, Int. J. Coal Geol., 68, 205-222, doi:10.1016/j.coal.2006.02.005, 2006.

Nakashima, Y. and Nakano, T.: Optimizing contrast agents with respect to reducing beam hardening in nonmedical X-ray computed tomography experiments, J. Xray Sci. Technol., 22, 91103, doi:10.3233/xst-130411, 2014.

Nemoto, K., Watanabe, N., Hirano, N., and Tsuchiya, N.: Direct measurement of contact area and stress dependence of anisotropic flow through rock fracture with heterogeneous aperture distribution, Earth Planet. Sci. Lett., 281, 81-87, doi:10.1016/j.epsl.2009.02.005, 2009.

Oh, J., Kim, K.-Y., Han, W. S., Kim, T., Kim, J.-C., and Park, E.: Experimental and numerical study on supercritical $\mathrm{CO}_{2}$ /brine transport in a fractured rock: Implications of mass transfer, capillary pressure and storage capacity, Adv. Water Resour., 62, Part C, 442-453, doi:10.1016/j.advwatres.2013.03.007, 2013.

Oron, A. P. and Berkowitz, B.: Flow in rock fractures - The local cubic law assumption reexamined, Water Resour. Res., 34, 28112825, doi:10.1029/98wr02285, 1998.

Patankar, S. V. and Spalding, D. B.: A calculation procedure for heat, mass and momentum transfer in three-dimensional parabolic flows, Int. J. Heat Mass Transfer, 15, 1787-1806, doi:10.1016/0017-9310(72)90054-3, 1972.

Perrin, J.-C. and Benson, S.: An experimental study on the influence of sub-core scale heterogeneities on $\mathrm{CO}_{2}$ distribution in reservoir rocks, Transp. Porous. Med., 82, 93-109, doi:10.1007/s11242009-9426-x, 2010.

Pfrang, A., Schladitz, K., Wiegmann, A., and Schimmel, T.: Calculation of the evolution of surface area and free volume during the infiltration of fiber felts, Chemical Vapor Deposition, 13, 705715, doi:10.1002/cvde.200706590, 2007.

Pini, R. and Benson, S. M.: Simultaneous determination of capillary pressure and relative permeability curves from core-flooding experiments with various fluid pairs, Water Resour. Res., 49, 35163530, doi:10.1002/wrcr.20274, 2013.

Pini, R., Krevor, S. C. M., and Benson, S. M.: Capillary pressure and heterogeneity for the $\mathrm{CO}_{2}$ /water system in sandstone rocks at reservoir conditions, Adv. Water Resour., 38, 48-59, doi:10.1016/j.advwatres.2011.12.007, 2012.

Pippan, R. and Gumbsch, P.: Multiscale modelling of plasticity and fracture by means of dislocation mechanics, Springer Science \& Business Media, New York, 2010.

Pritchard, G.: Anti-corrosion polymers: PEEK, PEKK and other polyaryls, 8, Rapra Technology Ltd., Shawbury/Shrewsbury/Shropshire, UK, 1994.

Pudlo, D., Henkel, S., Enzmann, F., Heister, K., Werner, L., Ganzer, L., Reitenbach, V., Albrecht, D., and Gaupp, R.: The relevance of mineral mobilization and dissolution on the reservoir quality of sandstones in $\mathrm{CO}_{2}$ storage sites, Energy Procedia, 59, 390-396, doi:10.1016/j.egypro.2014.10.393, 2014.

Pyrak-Nolte, L. J. and Morris, J. P.: Single fractures under normal stress: The relation between fracture specific stiffness and fluid flow, Int. J. Rock Mech. Min., 37, 245-262, doi:10.1016/S13651609(99)00104-5, 2000.

Rangel-German, E., Akin, S., and Castanier, L.: Multiphase-flow properties of fractured porous media, J. Petroleum Sci. Eng., 51, 197-213, doi:10.1016/j.petrol.2005.12.010, 2006.

Re, F. and Scavia, C.: Determination of contact areas in rock joints by X-ray computer tomography, Int. J. Rock Mech. Min., 36, 883-890, doi:10.1016/S0148-9062(99)00056-X, 1999.

Ren, J. and Ge, X.: Computerized tomography examination of damage tests on rocks under triaxial compression, Rock Mech. Rock Eng., 37, 83-93, doi:10.1007/s00603-003-0007-y, 2004.

Rücker, M., Berg, S., Armstrong, R. T., Georgiadis, A., Ott, H., Schwing, A., Neiteler, R., Brussee, N., Makurat, A., Leu, L., Wolf, M., Khan, F., Enzmann, F., and Kersten, M.: From connected pathway flow to ganglion dynamics, Geophys. Res. Lett., 42, 3888-3894, doi:10.1002/2015gl064007, 2015.

Rutqvist, J. and Stephansson, O.: The role of hydromechanical coupling in fractured rock engineering, Hydrogeol. J., 11, 7-40, doi:10.1007/s10040-002-0241-5, 2003.

Sahimi, M.: Flow and transport in porous media and fractured rock: from classical methods to modern approaches, John Wiley \& Sons, Weinheim, Germany, 2011.

Santos, J., Vargas, E., Barroso, E., Castro, J., Gonçalves, C., and Campos, E.: Studies of mechanisms associated with sand production using X-ray CT scan, in: Advances in X-ray Tomography for Geomaterials, edited by: Desrues, J., Viggiani, G., and Besuelle, P., ISTE Ltd., London, UK, 199-205, 2010.

Schembre, J. M. and Kovscek, A. R.: A technique for measuring two-phase relative permeability in porous media via X-ray CT measurements, J. Petrol. Sci. Eng., 39, 159-174, doi:10.1016/S0920-4105(03)00046-9, 2003.

Schwarz, J.-O. and Enzmann, F.: Simulation of Fluid Flow on Fractures and Implications for Reactive Transport Simulations, Transp. Porous. Med., 96, 501-525, doi:10.1007/s11242-0120103-0, 2013.

Searle, O. B. and Pfeiffer, R. H.: Victrex poly(ethersulfone) (PES) and Victrex poly(etheretherketone) (PEEK), Polymer Eng. Sci., 25, 474-476, doi:10.1002/pen.760250808, 1985.

Shi, J.-Q., Xue, Z., and Durucan, S.: History matching of $\mathrm{CO}_{2}$ core flooding CT scan saturation profiles with porosity dependent capillary pressure, Energy Procedia, 1, 3205-3211, doi:10.1016/j.egypro.2009.02.104, 2009.

Snow, D. T.: A parallel plate model of fractured permeable media, Thesis (PhD), University of California, Berkeley, 359 pp., 1965.

Swan, G.: Determination of stiffness and other joint properties from roughness measurements, Rock Mech. Rock Eng., 16, 19-38, doi:10.1007/bf01030216, 1983.

Tatone, B. A. and Grasselli, G.: Characterization of the effect of normal load on the discontinuity morphology in direct shear specimens using X-ray micro-CT, Acta Geotech., 10, 31-54, doi:10.1007/s11440-014-0320-5, 2015.

Tsang, Y. W.: The effect of tortuosity on fluid flow through a single fracture, Water Resour. Res., 20, 1209-1215, doi:10.1029/WR020i009p01209, 1984.

Tsuchiyama, A., Uesugi, K., Nakano, T., and Ikeda, S.: Quantitative evaluation of attenuation contrast of X-ray computed tomography images using monochromatized beams, Am. Mineral., 90, 132-142, doi:10.2138/am.2005.1552, 2005. 
Van Geet, M. and Swennen, R.: Quantitative 3-D-fracture analysis by means of microfocus X-ray computer tomography $(\mu \mathrm{CT})$ - An example from coal, Geophys. Res. Lett., 28, 3333-3336, doi:10.1029/2001g1013247, 2001.

Vandersteen, K., Busselen, B., Van Den Abeele, K., and Carmeliet, J.: Quantitative characterization of fracture apertures using microfocus computed tomography, Geological Society, London, Special Publications, 215, 61-68, doi:10.1144/gsl.sp.2003.215.01.06, 2003.

Vinegar, H. J., De Waal, J. A., and Wellington, S. L.: CT studies of brittle failure in castlegate sandstone, Int. J. Rock Mech. Min., 28, 441-450, doi:10.1016/0148-9062(91)90082-W, 1991.

Walsh, J. B.: Effect of pore pressure and confining pressure on fracture permeability, Int. J. Rock Mech. Min., 18, 429-435, doi:10.1016/0148-9062(81)90006-1, 1981.

Wang, H. F.: Theory of linear poroelasticity with applications to geomechanics and hydrogeology, Princeton University Press, Princeton, NJ, 2000.

Watanabe, N., Hirano, N., and Tsuchiya, N.: Determination of aperture structure and fluid flow in a rock fracture by highresolution numerical modeling on the basis of a flow-through experiment under confining pressure, Water Resour. Res., 44, W06412, doi:10.1029/2006wr005411, 2008.

Watanabe, N., Hirano, N., and Tsuchiya, N.: Diversity of channeling flow in heterogeneous aperture distribution inferred from integrated experimental-numerical analysis on flow through shear fracture in granite, J. Geophys. Res.-Sol. Ea., 114, B04208, doi:10.1029/2008jb005959, 2009.

Watanabe, N., Ishibashi, T., Ohsaki, Y., Tsuchiya, Y., Tamagawa, T., Hirano, N., Okabe, H., and Tsuchiya, N.: X-ray CT based numerical analysis of fracture flow for core samples under various confining pressures, Eng. Geol., 123, 338-346, doi:10.1016/j.enggeo.2011.09.010, 2011.
Watanabe, N., Ishibashi, T., Tsuchiya, N., Ohsaki, Y., Tamagawa, T., Tsuchiya, Y., Okabe, H., and Ito, H.: Geologic core holder with a CFR PEEK body for the X-ray CT-based numerical analysis of fracture flow under confining pressure, Rock Mech. Rock Eng., 46, 413-418, doi:10.1007/s00603-012-0311-5, 2013.

Weerakone, W. M. S. B. and Wong, R. C. K.: Characterization of Variable Aperture Rock Fractures Using X-ray Computer Tomography, in: Advances in X-ray Tomography for Geomaterials, edited by: Desrues, J., Viggiani, G., and Besuelle, P., ISTE LTd., London, UK, 229-235, 2010.

Weissbrod, T. and Sneh, A.: Sedimentology and paleogeography of the Late Precambrian-Early Cambrian arkosic and conglomeratic facies in the northern margins of the Arabo-Nubian Shield, Bulletin (Makhon ha-ge'ologi (Israel)), no. 87., Geological Survey of Israel, Jerusalem, 2002.

Witherspoon, P. A., Wang, J. S. Y., Iwai, K., and Gale, J. E.: Validity of cubic law for fluid flow in a deformable rock fracture, Water Resour. Res., 16, 1016-1024, doi:10.1029/WR016i006p01016, 1980.

Zhou, X. P., Zhang, Y. X., and Ha, Q. L.: Real-time computerized tomography (CT) experiments on limestone damage evolution during unloading, Theor. Appl. Fracture Mech., 50, 49-56, doi:10.1016/j.tafmec.2008.04.005, 2008.

Zimmerman, R. W. and Yeo, I.-W.: Fluid flow in rock fractures: From the Navier-Stokes equations to the cubic law, in: Dynamics of Fluids in Fractured Rock (Geophysical Monograph Series 162), edited by: Faybishenko, B., Witherspoon, P. A., and Gale, J. E., American Geophysical Union, Washington, D.C., 213-224, 2013.

Zimmerman, R. W., Chen, D.-W., and Cook, N. G. W.: The effect of contact area on the permeability of fractures, J. Hydrol., 139, 79-96, doi:10.1016/0022-1694(92)90196-3, 1992. 